\title{
O USO DO JOGO EDUCATIVO NO ENSINO DA ENFERMAGEM
}

Maguida Costa Stefanelli *

STEFANELLI, M.C. O uso do jogo educativo no ensino da enfermagem. Rev. Esc.

Enf. $U S P$, v. 25, n. 3, p. 347-61, dez. 1991.

É apresentada ampla revisūo de literatura sobre o uso do jogo educativo como 'stratégia de ensino na educação em geral e, mais especificamente na enfermagem- insino, educaçio para a saude e educação continuada. enfermagem.

UNITERMOS: Jogo educativo em enfermagem. Ensino de comunicação em

\section{INTRODUÇÃO}

A qualidade da comunicação que ocorre entre a enfermeira e o paciente é algo preocupante, uma vez que competência em comunicação é pouco encontrada na prática. Isto já foi observado pela Autora deste estudo, também entre enfermeiras que foram suas alunas o que a incentiva a continuar o aprimoramento do ensino sobre a utilização da comunicação em enfermagem. Nós acreditamos que a "competência interpessoal" pode ser adquirida pela enfermeira, se ela receber, na sua formação profissional ou em programas de educação continuada, a informação necessária sobre comunicação e sobre sua utilização na enfermagem, principalmente quanto à comunicação interpessoal, pois esta, em geral, permeia as demais ações da profissão. (STEFANELLI, 1985 e 1990).

Estimulada por uma das estratégias de ensino utilizadas durante o "Seminário de Educação para o Autocuidado em Saúde", oferecido pelo Programa de Pós-Graduação da Escola de Enfermagem da Universidade de São Paulo, começamos a procurar literatura profissional que nos auxiliasse a aplicar, no ensino da comunicação, a estratégia de ensino utilizada, neste evento, com o objetivo de facilitar o aprendizado das alunas do curso de graduação em enfermagem.

ROSENDAHL (1974) afirma que é necessário atender às necessidades de aprendizagem do adulto, no caso enfermeiras e alunas de enfermagem; aborda, ainda a importância de usar estratégias de ensino que aproveitem ao máximo as experiências anteriores das pessoas, dando

\footnotetext{
* Infermelra. Professor Assoctado do Departamento de Bnfermagem Materno-Infantil e Pstquiátrica da Fro-USP - disciplina Enfermagem Psiquiátrica.
} 
ênfase à participação e ao envolvimento ativo das alunas. Assegura que isto é um meio de provocar experiências significativas para o aprendizado. Segundo esta autora, as enfermeiras educadoras devem dar menos respostas e fazer mais perguntas para que, na aluna, o processo intelectual seja estimulado. Considera o jogo simulado como uma estratégia que pode atingir essa finalidade.

Antes de abordarmos a literatura em enfermagem, sobre o assunto, apresentamos uma revisão sucinta sobre o conceito dos termos "jogo", "simulação" e "jogo simulado" e a utilização do jogo como estratégia de ensino em outras áreas.

O jogo, para DAY (1973) e SLEET; CORBIN (1979), é uma atividade entre jogadores, operando sob determinadas regras para que seja atingido um objetivo. Para estes autores "jogar" é um modo de vida, embora até recentemente pouco se conhecesse sobre a importância do jogo na vida das pessoas. Segundo os mesmos autores, o jogo, mesmo para a criança, não é somente divertimento, mas é também interagir com limites, experimentar, explorar, descobrir e aprender novas habilidades e desenvolver sua capacidade para viver. Comentam que o jogo é tão antigo quanto a própria civilização e citam exemplos de achados arqueológicos que apontam para a existência de jogos 3.500 A.C. Abordam a importância do jogo para a socialização e o preparo para a vida, se a simulação for considerada como um aspecto do jogo.

COLEMAN (1969), ao descrever a vida como um jogo, atribui-lhe as características formais de um jogo, ou seja, os jogadores têm um objetivo e agem na sua direção; suas ações são governadas por regras que especificam as ações proibidas e as permitidas; e há outras regras que podem ser estabelecidas durante o curso do jogo ou descobertas somente no decorrer do mesmo, que especificam as consequiências de cada ação ajudando ou inibindo o movimento de cada jogador em direção ao objetivo. Para COLEMAN os jogos não são mais que uma introdução à vida, são uma introdução à idéia de trabalhar em direção a um objetivo coletivo e de investigar o seu próprio ser na coletividade mais ampla.

Simulação, segundo CLARK (1977) e SLEET; CORBIN (1979), é uma limitação ou simplificação de algum aspecto da realidade. Está de acordo com algum aspecto da vida real e as atividades e papéis desempenhados são a réplica de um fenômeno correspondente numa determinada cultura.

Jogo simulado, segundo BLOOMER (1973) e SLEET; CORBIN (1979) é uma estratégia que combina as características do jogo (regras, competição, vencedores, ganhadores) com as da simulação (abstração de algum evento ou processo real).

Para RUBEN (1977) simulação, jogo e outros esquemas experienciais são compostos por papéis dos participantes, da interação entre estes, das regras que governam a interação, dos objetivos relacionados à finalidade das atividades e critérios para determinar o alcance dos objetivos e término da atividade. 
Segundo BECKER (1980), o jogo tem sido utilizado por diferentes culturas, refletindo uma situação de vida e é importante para o desenvolvimento do homem, porque permite o seu preparo para a vida futura, em uma situação menos estressante. Informa que jogos representando guerra foram criados há 2.000 anos pelos alemães, e foram aprimorados por ocasião da segunda guerra. Comenta que estes jogos militares representavam um método de analisar problemas e uma oportunidade para experimentar possiveis tentativas de soluções e sua eficiência, sem o risco das perigosas consequiências de um erro na situação real de guerra.

O jogo tem sido usado em diversas áreas como as da administração, comunicação, educação, sociologia entre outras com os objetivos de incentivar criatividade, tomada de decisão, participação, interação, diminuição do estresse ao enfrentar situações reais, interesse pelo conhecimento, bem como de facilitar o aprendizado (GREENBLAT, 1977; LIGGET, 1977; MALLEN, 1973; MARSHAL et al. 1982; PERFY, 1977; SLEET; CORBIN, 1978; THIAGARAJAN, 1977, entre outros).

Na bibliografia anotada, sobre jogos simulados na educação em saúde, SLEET; STADSKLEV (1977) apresentam 69 jogos que, de modo geral, estão relacionados à doença, uso e abuso de drogas, ecologia, planejamento familiar, sexualidade humana, nutrição, planejamento do cuidado da saúde, esses autores alertam para o problema de alguns jogos, já comercializados, apresentarem distorções e visão não realística dos problemas de saúde.

$\mathrm{Na}$ área da saúde e em enfermagem, o jogo, a simulação ou o jogo simulado também têm sido utilizados ao longo do tempo e, praticamente, acompanhado o desenvolvimento do seu uso em outras áreas.

Várias enfermeiras têm escrito sobre este tema afirmando que a utilização do jogo no ensino promove interação e envolvimento entre os participantes, estimula interesse em um determinado tópico e provê elementos para mudança de atitude (ALEXANDER, 1986; SILVA; DECK, 1989; WALLJASPER, 1982; YANTZIE, 1980 entre outros).

CLARK (1977), COOPER (1979), DANIEL et al. (1977), DEARTH \& MACKENZIE (1975), LINCOLN et al. (1978), LOWE (1975) e ROTTET (1974), WOLF; DUFFY (1979) estão entre as pioneiras no uso do jogo, jogo simulado e simulação na enfermagem.

WOLF; DUFFY (1979) apresentam, em publicação da National League for Nursing, parte de um seminário sobre "Simulação e Jogo: Estratégia para o Ensino". Os objetivos foram: identificar a analisar a "simulação" e o "jogo" aplicáveis à enfermagem, explorar aspectos educacionais de ambos, determinar vantagens e desvantagens do seu uso na educação de enfermagem, identificar componentes essenciais no delineamento de um jogo e determinar métodos de avaliação de jogo e simulação. Declaram que o jogo simulado é uma estratégia de ensino que tem recebido atenção dos educadores que o emprega na educação e no treinamento com os seguintees propósitos: apresentar informação; exercitar comportamentos da vida real num universo simulado; avaliar desempenho; e estimular respostas a situações encontradas. 
Para uso do jogo na enfermagem as autoras acima referidas identificam questões sobre o papel do professor, o tempo e o espaço exigidos, propriedade dos jogos, procedimentos de avaliação, benefícios e suas desvantagens. As autoras acreditam que o jogo é útil para aliviar o estresse do confronto com a realidade, desde que elaborado criteriosamente. Comentam vários jogos já utilizados na área da enfermagem e concluem com o alerta de que o jogo simulado não é panacéia para todos os problemas do ensino de enfermagem e que, ao usá-lo, a enfermeira educadora deve considerar suas vantagens e desvantagens.

COOPER (1979) refere-se ao uso de jogos em escolas rurais antes do término do século XIX, e o uso do jogo na Prússia como parte do treinamento militar. Define-o como uma atividade executada por um ou mais jogadores, cujas ações são reguladas por uma série de regras explicitas, sendo seu término pré-determinado. Segundo COOPER (1979) a escassez de jogos específicos para a enfermagem cria um problema, pois a sua utilização requer tempo, imaginação e habilidade. Para ela os jogos podem ser simples como os de trilha, se forem usadas regras para determinação de como os jogadores devem agir para atingir os objetivos propostos. Jogos muito complexos são desestimulantes. O jogo deve ser delineado de modo que os usuários se envolvam com ele. Dependendo da complexidade pode ter direçöes orais ou escritas. Esta autora utilizou o jogo para apreciar a aprendizagem que resultou da educação de um grupo de hipertensos.

$O$ uso do jogo e simulação pode oferecer uma significativa contribuição para a aprendizagem, pois provê uma experiência central comum para todos os membros do grupo: a oportunidade de cada membro aprender com o outro; além disso promove ativa participação e interação entre os membros do grupo. Uma discussão após o jogo é indicada para rever conceitos e oferecer reforço necessário. Pode ser usado em educação contínua e deve ser cuidadosamente planejado (COOPER, 1979).

Surgiu, recentemente, outra publicação de COOPER (1989), sobre a importância do uso da criatividade no ensino da enfermagem, a fim de vencer o cansaço do professor, de ensinar anos e anos o mesmo assunto. A autora considera o jogo como uma das estratégias a serem utilizadas no ensino. Cita, como novidade os jjogos utilizados na televisão (TV); comenta que os programas de jogos da TV e outros jogos triviais podem facilmente ser adaptados ao ensino e oferece algumas diretrizes sobre como elaborar um jogo com base em programa de TV. Sugere discussão em grupo para que novas idéias possam surgir.

Ao descrever a utilidade do "jogo acadêmico", como o chama FRENCH (1980), para a educação da enfermeira, este autor comenta que os resultados sugerem que as alunas desenvolvem, no jogo, seus conhecimentos sobre o assunto em foco; comenta, entretanto que este pode ser mais útil como método de consolidação. Um resultado interessante de seu trabalho foi que as alunas afirmaram preferir o jogo à filme, leitura e discussão; atribuiram, porém, quase o mesmo valor à exposição ou conferência. O grupo que parece ter-se beneficiado mais teve 
uma série de sessões de ensino antes do jogo. Este achado fala a favor da complementação da preleção pelo jogo. HARTSOCK; LANGE (1987), comentam sobre a eficiência do jogo para revisão de conteúdo.

Segundo DAVIDHIZAR (1982), o uso apropriado do jogo pode estimular o interesse da estudante nas atividades em classe, e o seu envolvimento na aprendizagem; pode auxiliá-la a reter conceitos sobre o assunto a ser aprendido. A concentração da estudante aumenta quando o jogo estimula seu interesse. O processamento da informação durante o jogo pode provocar retenção dos conceitos aprendidos. A aluna deve ser estimulada a criar seu próprio jogo devido ao alto custo do mesmo.

O jogo simulado é preconizado por ULIONE (1983) como um instrumento didático para o ensino de conteúdo específico, como, por exemplo, medicação, fases do relacionamento terapêutico enfermeira-paciente, assistência a idosos; pode ser usado também para prover solução de problema ou partilhar informações, de acordo com os objetivos instrucionais.

Preocupada com as idéias estereotipadas das enfermeiras sobre o cuidado do idoso, ASTHLL - McNISH (1984) elaborou jogo que teve sua eficiência demonstrada na mudança de atitude das mesmas em relação a esses pacientes, bem como nas suas respostas emocionais e padrões de comunicação. Durante o jogo algumas representaram o papel de quem ministrava cuidado e outras, o de idosos.

Para LOWE (1975) jogo e simulação na educação em enfermagem são estratégias eficientes, que estimulam a participação ativa da aluna, e recomenda alguns critérios para o seu uso: a aprendizagem deve ser centrada na aluna; a pessoa aprende melhor quando "faz por si mesmo"; e as pessoas são motivadas a fazer o que lhes agrada, portanto a aprendizagem deverá ser um processo agradável. Chama, também, a atenção para algumas características das alunas que devem ser consideradas, como diferença de idade, comportamento de entrada. LOWE (1975) tece, ainda, comentários sobre a possibilidade da existência do jogo individual para atender a estas características propiciando diferentes tipos de aprendizagem além de ser uma forma da aluna se preparar para se beneficiar com o uso do jogo em grupo, isto é, aprender com os pares, receber respostas ao seu comportamento e desenvolver habilidades em comunicação, que é vital em enfermagem. $O$ aprendizado com pares pode ser mais efetivo quando ocorre pelo uso do jogo simulado.

Para despertar a consciência dos profissionais de saúde sobre os problemas decorrentes da hemofilia, GAGNON; GREENBLAT (1977) criaram um jogo que, segundo eles, tem sido promissor para facilitar o planejamento de cuidados do hemofílico; por meio da discussão os participantes adquirem maior compreensão dos problemas apresentados pela pessoa com hemofilia.

ATKINSON (1977) relata como utilizou o jogo para ensinar profissionais da área da saúde, envolvendo-os, mais precocemente nas situações mais variadas possíveis; usou jogo, simulação e jogo simulado; com o envolvimento dos participantes estes perceberam o significado do jogo si- 
mulado e o que ele pode ou não ofereccr. O autor recomenda, ainda, a necessidade de conhecimento e habilidade para elaboração de um jogo educativo e seleção do assunto apropriadamente.

DUKE (1986) apresenta um resumo da evolução histórica do uso do jogo nas guerras, como preparo militar, principalmente na Inglaterra, França Austria, Prússia, Itália, Turquia, Japão e USA, antes do fim do século XIX. O uso desta estratégia perdurou por mais ou menos 150 anos antes de sua principal aplicação, isto é, na área de administração, com foco na tomada de decisão. A partir daí houve proliferação de jogos na indústria, no comércio e em escolas de administração, entre outros.

O mesmo autor identificou 29 jogos e simulações existentes na literatura de enfermagem, que classificou em três tipos: clínico, físiopatológico e psicossocial. Ao realizar seu trabalho sobre taxonomia dos jogos e simulação, teve como objetivo tornar disponivel, para a educação em enfermagem, a literatura existente sobre o assunto e demonstrar como, nela, podem ser utilizados jogos instrucionais. Afirma que eles podem ser apropriados à aprendizagem individual e independente, e que, uma vez identificados e classificados podem ser usados, testados e aperfeiçoados; e que alguns, como os da área de administração, das ciências sociais e de outros campos da saúde já poderiam ser usadas pela enfermagem. Acredita que o jogo é uma das formas que poderiamos usar para enfrentar o desafio de integrar as teorias de enfermagem na prática.

Encontramos duas publicações sobre a utilização do jogo no ensino de modelo conceitual e teorias de enfermagem (HOON, 1986; AGGLETON; CHALMERS, 1987 e CESSARIO, 1987).

O jogo é visto por HONN (1986) como um novo modo de estudo de modelos de enfermagem; apresenta as premissas principais de alguns modelos em cartas e também algumas mensagens sobre condições do paciente que foram chamadas de "obstáculos". Em algumas cartas aparece a palavra morte e a autora comenta que, em geral, as teorias não ensinam como lidar com esta e que em algumas a morte é apenas citada. Segundo esta autora, ao utilizar o jogo elaborado a aluna não encontra respaldo teórico para resolver "o obstáculo" morte. Afirma que nenhum modelo por si só é completo e, portanto, não pode ser constiuído em marco conceitual único para a disciplina de enfermagem.

CESSARIO (1987) apresenta o jogo como estratégia de ensino, principalmente nas escolas de administração, e comenta que na enfermagem este tem sido utilizado como reforço e motivação para a aprendizagem. Seus objetivos, ao elaborar um jogo sobre modelos conceituais de enfermagem, são reforço e motivação para a aprendizagem. Ressalta que o jogo deve agradar as alunas e propiciar-lhes recursos para comparar um modelo de enfermagem com outro, perceber semelhanças e diferenças entre os quatro principais conceitos abordados nas teorias de enfermagem: pessoa, ambiente, enfermagem e saúde. Para este autor os objetivos do jogo são: capacitar o aluno a comparar modelos de enfermagem; encorajar a interação entre alunas e professor e oferecer uma 
estratégia de ensino agradável que torne a aprendizagem um momento de descontração. Pode, ainda, ser usado individualmente ou por três ou quatro jogadores. Considera, o autor, que atingiu os objetivos propostos e estimula os educadores a criarem jogos para utilização no ensino.

Segundo HENRY (1986), a receptividade dos participantes para com os jogos é um dos meios para a resolução de problemas da educação em serviço; afirma que a chave para provocar esta recepção é criar o entusiasmo entre os membros da equipe e perguntar: "o que melhor que um jogo para rever conhecimentos?" Para a autora o jogo não somente desafia e envolve os membros da equipe como também oferece competição saudável, promove camaradagem e sentimento positivo. Usado como estratégia educacional pode aumentar o conhecimento, reforçar a informação e clárificar mal-entendidos. $O$ jogo criado por esta autora apresenta várias questões sobre centro cirúrgico como procedimentos, esterilização, custos e anestesia.

DE BLOIS (1987) utiliza jogo com enfermeiras de centro cirúrgico para que elas adquiram consciência da necessidade de contenção de custos, percebendo o preço real dos itens utilizados nas salas de operações; sendo assim, passarão a usar, criteriosamente, o suprimento existente e a cuidar efetivamente de sua conservação. A autora acredita ter atingido os objetivos com base na avaliação do jogo feito pelas enfermeiras: excelente idéia; gostariam de conhecer mais o assunto; é agradável e informativo; mais do mesmo e outro (jogo) por favor; foi bastante agradável e nós aprendemos muito.

ROTHROCK (1986) preocupada com o conflito e incerteza que as enfermeiras recém-formadas apresentam no cuidado peri-operatório dispensado ao paciente e com a frustração e fadiga das enfermeiras mais experientes, ao tentarem encontrar meios a fim de sanar este conflito, introduziu um jogo simulado para provocar o entrosamento de ambos os grupos de enfermeiras, estes grupos reconheceram que por meio de discussão, negociação e tentativas de compreensão mútua as concepções errôneas puderam ser corrigidas e 0 conflito diminuído. $\mathrm{O}$ jogo simulado com suas regras atuou como elemento facilitador da adaptação das enfermeiras ao centro cirúrgico.

McCLEAN (1983) utilizou com sucesso o jogo para provocar mudança de atitude e de comportamento nas enfermeiras de centro cirúrgico em relação à técnicas de esterilização de material.

Outro estudo recente sobre jogo como estratégia de ensino a ser utilizado pelas enfermeiras educadoras é o de LEWIS et al. (1989). Estes autores selecionaram um jogo como estratégia de ensino por considerálo um processo interativo que facilita a aquisição e aplicação de conhecimentos e habilidades cognitivas, afetivas e psicomotoras. Esse estudo corrobora os de JOOS (1984), KOLB (1963), PLASTERER; MILLS (1983) e WOLF; COGGINS (1981). Segundo tais autores, a oportunidade para discussão durante o jogo aumenta o interesse e a motivação, facilita a assimilação de conceitos pela estimulação do processo cognitivo, 
permite a expressão de opiniōes, esclarece conceitos, reforça e suplementa a aprendizagem e promove positiva aprendizagem afetiva.

Quanto a critérios para se verificar se o jogo é adequado ao assunto a ser estudado, estes são citados por LEWIS et al (1989) sob a forma de perguntas: o jogo satisfaz os objetivos do programa? Pode ser utilizado dentro do tempo disponivel? O tamanho da sala e sua disposição são adequados? A disponibilidade assegura um número mínimo de jogadores exigido? Os membros da equipe têm tempo e interesse para criar ou adaptar jogos? Se não, há recursos disponíveis para comprá-los?

ANGEL (1983) apresenta um jogo sobre o cuidado utilizado para a orientação de um paciente diabético de 63 anos que não conseguia entender seu distúrbio; como ele havia sido maquinista de estrada de ferro ela utilizou um desenho de trem, familiar para o paciente, e estabeleceu analogia com a diabete.

MARZOLO P. (1989) elabovou um jogo para educação sobre AIDS. Os usuários do ambulatório são convidados, pelo Ministério da Saúde do Chile, para assistir a um vídeo sobre o tema, devendo a sua participação ser livre e espontânea. Logo a seguir são convidados para participar de um jogo "Quem sabe mais sobre a AIDS", que tem, como objetivos avaliar o conhecimento, sobre esse assunto, de uma determinada população levando-a a: expressar e compartilhar inquietações sobre a doença em pauta; identificar mecanismos de transmissão do vírus da imunodeficiência humana (HIV); estimular reflexão sobre a responsabilidade que cabe a cada cidadão na prevenção e controle do HIV. A autora utilizou 19 fichas contendo informações sobre AIDS com o fim de atingir os objetivos citados.

ENGELKE (1983) utilizou o jogo simulado para ensinar a estudante a ajudar os pacientes com deficiência neurológica a enfrentarem seus problemas. As atlerações mais comuns destes são as das funções motora, sensorial, da linguagem, da memória, de concentração e da habilidade em solucionar seus problemas. Com estas alterações surge uma situação em que a aluna tem de adaptar princípios de ensino e aprendizagem para atender as necessidades específicas de cada paciente, o que a utilização de um jogo, elaborado pela autora, torna possivel. A avaliação das estudantes tem sido positiva e o estilo diferente de aprendizagem bem aceito.

SANCHEZ et al (1988) afirmam que na cultura chilena o jogo é usado para entretenimento e faz com que as pessoas deixem de lado, temporariamente, os problemas de vida diária e suas preocupações. Como enfermeiras educadoras para o autocuidado, estas autoras sentiram necessidade de usar técnicas que pudessem envolver o usuário em todas as etapas do método educativo e, a partir de 1984, começaram a envidar esforços para descobrir e desenvolver jogos educativos. Essas autoras informam que atualmente o jogo está incorporado, como técnica educativa, em todos os programas do Centro de Diagnóstico para o Autocuidado da Pontifícia Universidade Católica do Chile. 
Declaram SANCHEZ et al (1988) que o jogo estimula o diálogo, a participação e a fixação da atenção e estimulam, nos participantes, uma sã e amistosa competição que gratifica tanto usuários como profissionais.

Os mesmos autores definem o objetivo do jogo como "técnica de educação para o autocuidado" e apresentam suas características, os elementos necessários para sua utilização, bem como suas vantagens e limitações e recomendam jogos simples e motivadores em linguagem compreensível pelós usuários; que seu ritmo seja dado pelo grupo que o joga; que não sejam massificados e que sejam criados para apoiar o desenvolvimento de programas educativos específicos.

Na enfermagem o maior número de jogos é encontrado na área da administração. Em geral são eles relativos a tomada de decisões, comunicação e relacionamento da enfermeira com o pessoal da equipe e preparo da recém-formada para assumir a administração de serviços de enfermagem. Os objetivos dos jogos são: estabelecer um vínculo entre teoria e prática, diminuir a ansiedade e frustração da enfermeira ao assumir seu novo papel, facilitar seu aprendizado sobre como lidar com a organização e implementar os objetivos desta. O jogo simulado pode oferecer à enfermeira o sentimento de estar realmente sendo envolvida na formulação da solução de problemas e pode tornar a prática menos traumatizante (NOWAK; ADAMS, 1988; PLASTERER; MILLS, 1983, SMITH, 1983).

SYLVESTER (1974) considera o jogo, no ensino de administração, como um elo adequado entre a teoria e a situação real de vida; acredita que o jogo simulado oferece um cunho de realidade que permite o envolvimento da enfermeira em experiências de solução de problema na administração em enfermagem e apresenta a descrição e as vantagens do jogo. Afirma que aulas e leituras programadas são apenas parte da informação necessária, pois a enfermeira tem de aprender a desempenhar sua função, cabendo ao professor oferecer à estudante de enfermagem a oportunidade de experiências que lhe permitam a aplicação de conceitos e aquisição de habilidade em administração, o que é obtido por meio dos jogos administrativos.

Um jogo simulado para estudantes de profissões da saúde foi delineado por DEARTH; MAKENZIE (1975), tendo como premissa básica que problemas são mais efetivamente solucionados quando todos os ângulos e pontos de vista do problema são tomados em conjunto, com o que concorda DE BELLA-BALDIGO (1984). Esse jogo consta de um problema com várias perguntas sobre a sua solução; participam três grupos compostos de enfermeiras, adiministradores e médicos, em proporções diferentes, em cada grupo, que expõem seus pontos de vista sobre a situação problema. Um juri decide qual é o grupo vencedor. As autoras têm ficado satisfeitas com a avaliação de enfermeiras educadoras e chamam a atenção sobre o contínuo aperfeiçoamento necessário a todo jogo.

A organização do cuidado da saúde contém seu próprio arranjo de papéis e responsabilidades, formalmente distribuídos em padrões hierár- 
quicos, uma rede de poder e um intrincado sistema de comunicação; paralelamente há uma rede informal de relacionamento pessoal e social, que opera constantemente. Para tratar cada paciente de modo profissional e oferecer-lhe cuidado individualizado os membros da equipe devem ser capazes de trabalhar independentemente, dentro desta estrutura organizacional. Para FELDMAN (1985), um jogo simulado pode aguçar a habilidade de que as enfermeiras necessitam para encontrar seu próprio caminho nesta malha organizacional. Afirma que 0 jogo pode ser utilizado em sala de aula e com qualquer grupo organizacional ou população.

WASHBURN; McGINTY (1977) apresentam um jogo computadorizado para dar à aluna a compreensão do ambiente de trabalho, dos sistemas de oferecimento de cuidado para a saúde. O jogo permite observar a interação entre o pessoal que trabalha nos diferentes sistemas e entre estes e a comunidade.

Também no ensino da ética o jogo tem sido usado. WHITE; DAVIS (1987) abordam a dificuldade das alunas de graduação e pós-graduação em analisar cuidadosamente as situações práticas envolvendo ambiguidade ética e moral. Ressaltam ser realmente importante que as experiências de aprendizagem nas áreas de filosofia e ética relacionadas à enfermagem sejam criteriosamente examinadas e programadas para atender às necessidades das alunas. Comentam que, em geral, estas não chegam com conhecimento suficiente sobre ética e filosofia e propõem que os jogos sejam utilizados como estratégia de ensino apropriada, por docentes de enfermagem. Para essas autoras o jogo é uma estratégia que está entre a leitura e a experiência real.

Jogos como estratégias de ensino para o atendimento a emergências cárdio-pulmonares foram elaborados por WOODBERY; HAMRIC (1981) e SILVA E DECK (1989). O jogo de SILVA; DECK (1989) foi elaborado a partir da adaptação de vários programas de televisão; pelos resultados obtidos mostram eles sua eficiência. Foi a apatia das enfermeiras de uma equipe de enfermagem, a ansiedade das mesmas, o baixo índice de frequência em programas de educação em serviço e as limitadas oportunidades para desenvolvimento psicomotor que levaram as autoras, acima citadas, a criar uma estratégia que oferecesse ambiente descontraído, não ameaçador e que exigisse participação das enfermeiras. Os programas elaborados foram considerados pela população do estudo como excelentes. As autoras receberam vários comentários verbais após cada sessão e, um dos principais resultados foi o encaminhamento de outros membros da equipe para os programas de educação em serviço. As autoras destacam, ainda, que o programa aumentou a auto estima das enfermeiras e sua confiança no próprio desempenho. As pessoas se envolviam tanto no jogo que esqueciam que estavam aprendendo. Os administradores de unidade inundaram as autoras com pedidos de programas similares para unidades de cuidados intensivos, para neonatos e de pediatria.

SEIDL; DRESSEN (1978) imaginaram um jogo simulado como uma estratégia para ensinar a resolução de conflitos para alunas de pós-gra- 
duação; decorrido um ano as autoras ainda ouvem discussões, entre as participantes do jogo, sobre o impacto da experiência de aprendizagem e valem-se dela em suas experiências atuais com outros grupos de tomada de decisão. Acreditam que essa atitude está entre as melhores provas de uma vivência positiva de aprendizagem.

WALLJASPER (1982) apresenta, em seu trabalho, como o uso do jogo motivou a equipe de enfermagem a elaborar mais consistentemente planos de cuidado para o paciente.

O jogo tem um papel importante também no ensino do atendimento em situações de emergência, desastres e catástrofes. Os trabalhos de GOBLE (1982), HAGGARD (1984), YANTZIE (1980) são exemplos destes jogos. Nestes jogos, a competição é usada para estimular o pessoal da equipe a pensar realmente sobre o que fariam nas situações apresentadas.

O uso do jogo é um alívio agradável da rotina da leitura e discussão em sala de aula. Após o jogo elaborado para ensinar epidemiologia a alunas de enfermagem, ALFXANDER (1986) conclui que há envolvimento ativo por parte das alunas, em contraposição à passividade da leitura; opina que o barulho advindo da discussão entre alunas é a evidência de que o jogo encoraja participaçāo e interesse. Segundo a autora, a ênfase na competição é reduzida, uma vez que as participantes são avisadas que não há perdedores. Afirma que o jogo educativo em sala de aula é entretenimento para a aluna e trabalho para o professor, mas que o prêmio deste é resultado atingido. Para CLARK (1986) esta estratégia pode aumentar a confiança da aluna na experiência clínica real.

CRANCER; MAURY-HESS (1980), ao avaliarem o jogo como estratégia de ensino, afirmam que este é relacionamento interpessoal e comunicação e que o seu uso aumenta o conhecimento da aluna,provê alto nivel de envolvimento e oportunidade para a mesma tentar solucionar problemas e atingir respostas imediatas sobre tomada de decisão, sem riscos para o paciente e para a aluna. O resultado do seu estudo mostra a importância do envolvimento na aprendizagem. Ressalta que no currículo de sua escola há várias estratégias de ensino para atender a diferentes estilos cognitivos. Estes dados são corroborados por KOLB (1983).

Em enfermagem psiquiátrica temos um vasto campo para o emprego do jogo no ensino da comunicação enfermeira-paciente, do relacionamento terapêutico, do primeiro contato com a situação da assistência psiquiátrica, bem como para facilitar a compreensão do comportamento dos pacientes, das alunas, dos funcionários e as respectivas reações emocionais e para orientar pacientes e familiares.

Segundo CLARK (1977), o jogo simulado pode ser eficiente modo para avaliar e diminuir a ansiedade das alunas na interação com seus pacientes. $E$ oferecida à aluna, antes de interagir com o paciente a oportunidade de várias respostas. Destaca a autora que mais jogos devem ser criados, não só em enfermagem psiquiátrica como em todo programa educacional. 
Segundo LEYIN (1980), o jogo tem tanto conteúdo educacional como de entretenimento; relata que o jogo tem sido eficiente em uma unidade de adultos deficientes mentais.

SMOYAK (1977) fala sobre o uso do jogo simulado como instrumento que auxilia no diagnóstico e na terapêutica do paciente. Descreve sucintamente jogos a serem utilizados com indivíduos, casais, familias e pequenas organizaçōes que apresentam distúrbios de relacionamento. Menciona alguns para serem jogados entre cliente e terapeuta e afirma que o uso do jogo em unidade de tratamento aumenta a atividade e a responsabilidade do terapeuta para com o cliente. $O$ paciente torna-se um elemento participante no excitante processo de aprendizagem.

WINNEY; FORREST (1983) criaram um jogo de trilha para ajudar o paciente a manter-se na realidade concreta de vida, fora do hospital; é uma série de cartas contendo mensagens sobre alimentos, seu valor nutritivo, a vida social e o trabalho, entre outras atividades de vida diária. Ele pode ser jogado por dois ou três pacientes e um número igual de membros da equipe. $O$ jogo está sendo utilizado por unidades psiquiátricas governamentais da saúde.

Da revisão apresentada, podemos assegurar que a utilização do jogo tanto no ensino como na educação continuada e para a saúde pode provocar mudanças de atitude e comportamento nos que o utilizam, em todas as áreas da enfermagem.

Podemos, ainda, observar que o jogo é uma estratégia de ensino eficiente, que promove a integração não só entre professor e aluna como entre teoria e prática; é útil em diferentes estilos de aprendizagem; torna aluna e paciente elementos participativos nos processos de ensino-aprendizagem e de educação para a saúde. Promove, ainda, desenvolvimento da enfermeira e aluna, mudança de atitude e comportamento de ambas, além de preparar a aluna para a vida real.

Temos de usar a criatividade não só para elaborar novas estratégias de ensino como também de adaptar as já conhecidas ao momento em que vivenciamos o ensino.

STEFANELLI, M.C. The use of educative game in teaching nursing. Rev. Esc. Enf. $U S P$, v. 25, n. 3 , p. $347-61$, Dec. 1991.

In this article, an extensive review of the literature is presented concerned with the educative games as teaching strategy for general education and specifically for nursing education which includes: teaching, health education and continuing education.

UNITERMS: Educative game, teaching nursing.

\section{REFERENCIAS BIBLIOGRÁFICAS}

AGGLETON, P.; CHALMERS, H. Models of nursing: nursing practice and nurse education.

J. Adv. Nurs., จ. 12, n. 5, p.673-81, 1987.

ALdXXANDkR, M.A. Winning with games Nurse Edua, v. 11, n. 5, p.1986. 
ANGEL, S. The model ratlway. Nurs. Thmew, 7. 79, п. 9, p.62-3, 1983.

ASTILL-McNISH, S. A sensitization program for geriatric nurses: games that make you care. Can. Nurse, v. 80, n. 3, p. 18-24, 1984.

ATKINSON, F.D. Designing simulations and games: a workshop for health care professlonals. Health Fduc. Monogr., จ. 5, p.58-90, 1977. Supplement 1.

BECKFrR, C. An overview of simulation games and comments on their use in baccalaureate nursing education. Nurs. Papers, v. 12, n. 1/2, p.32-45, 1980.

BLOOMBR, J. What have almulation and game got to do with program learning and educational technology? Program. Learn. Iiduc. Teenol., v. 10, n. 4, p. 224-34, 1973.

CESSARIO, L. Utilization of board gaming for conceptual models of nursing. J. Nurm. Educ., v. 26, n. 4, p. 167-9, 1887.

CLARK, C.C. Learning outcomes in a simulation game for associate degree nursing students. Health Educ. Monoxr., v. 5, p. 18-27, 1977. Supplement 1.

CLARK, H.M. A health planning simulation game. Nurse Educ., v. 11, n. 4, p. 16-9, 1986.

COLfuMaN, J.S. Games as vehicles for social theory. Am. Behav. Scientiat, v. 12, p. 2-6, July/Aug. 1969.

COOPER, S.S. Methods of teaching - revisited game and simulation. J. Contin. Educ. Nurs., v. 10, n. 5, p. 14,47-8, 1979.

Teaching tips. J. Contin. Educ. Nurs., v. 20, n. 2, p. 95-6, 1989.

CRANCER, J.; MAURY-HIRSS, S. Games: an alternative to pedagogical instruction. J. Nurs. Educ., v. 19, n. 3, p. 45-62, 1980.

DANIEL, L. et al. Teaching caseload management. Nurs. Outlook, v. 25, n. 1, p. 27-9, 1977.

DAVIDHIZAR, R.E. Simulation games as a teaching technique in psychiatric nursing. Pergpect. Paychiatr. Care, v. 20, n. 1, p. 8-12, 1982.

DAY, K. Some theorical and pratical implication of one approache to simulation games. Program. Learn. Educ. Technol., v. 10, n. 4, p. 235-8, 1973.

DEARTH, S.; MACKENZIF, L. Synoptics: a simulation health professional students. J. Contin. Educ. Nurs., v. 6, n. 4, p. 28-31, 1975.

DE BELLA-BALDIGO, S. Fostering nurse' participation in health care planning. J. Nurs. Edue., Thorofare, v. 23, n. 3, D. 134-5, 1984.

DE BLOIS, C. Having fun with cost containment. AORN. J., v. 45, n. 6, p. 1446-7, 1987.

DUKE, E.S. A taxonomy of games and slmulations for nursing education. 'J. Nnrs. Edue., v. 25, n. 5, p. 197-206, 1986.

ENGELKE, M.K. Teaching the patient with a neurological deficit: a simulation experience. J. Neurosurg. Nurs., v. 15, n.'2, p. 107-11, 1983.

FELDMAN, H.R. The organization game. Nurs. Manag., v. 16, n. 9, p. 47-9, 1985.

FRENCH, P. Academic gaming in nurse education. J. Adv. Nurs., v. 5, n. 6, p. 601-12, 1980.

GAGNON, J.H.; GRFFENBLAT, C.S. Health care planning and education via gaming-gimulation: a two stage experiment. Health Educ. Monogr., v. 5, p. 42-52, 1977. Supplement 1.

GIRARD, N.L. A game-oriented strategy for teaching surgical terminology. Nurme Educ., v. 6, n. 5, p. 16, 1981.

GOBLE, J. Ten minutes in an air-raid shelter. Nurw. Mirror, v. 154, n. 9, p. VI-VIII, 1982.

GREFNBLAT, C.S. Gaming-simulation and health education: an overview. Health Dduc. Monogr., v. 5, p. 5-17, 1977. (Supplement 1). 
HAGGARD, A. A disaster game that prepares you for the real thing RN., v. 47, n. 10, p. 22-5, 1984 .

HARTSOCK, J.M.; LANGE, R.H. Trivia games: stimulating student learning. Nurse Educ., จ. 12, n. 1, p. 24-7, 1987.

HENRY, J. Using games to learn in the O.R. AORN J., v. 43, n. 4, p. 803-5, 1986.

HOON, E. Game playing: a way to look at nursing models. J. Adv. Nurs., v. 11, n. 4, p. 481-7, 1988.

JOOS, I.R.M. A teacher's guide for using games and slmulations. Nurse Educ., v. 9, n. 3, p. 28-8, 1984 .

KOLB, S.E. 3North: A game for teaching concepts of patient care. Nurwe Eduo., v. 8, p. 12-5, 1883.

LirYn, A. What's in a game? Nurs. Times, v. 76, n. 44, p. 1941-2, 1980.

LFWIS, D.J. et al. Gaming: a teaching strategy for adult learners. J. Contin. Idue. Nurs., v. 20, n. 2, p. 80-4, 1889.

LIGGETT, H. An evaluation instrument for use with urban simulation games. Simulation \& Games, v. 8, n. 2, p. 155-88, 1977.

LINCOLN, R. et al. Using simulated patients to teach assessment. Nurs. Outlook, v. 26, n. 5, p. 316-20, 1978.

LOWE, J. Games and simulations in nurse education. Nurs. Mirror, v. 141, n. 23, p. 68-9, 1975.

MALLen, G.L. The role of simulation in social education. Program. Laarn. Fduc. Teahnol., v. 10, n. 4, p. 248-68, 1973.

MARSHALL, S. et al. Developing communication skilis using simulation-gaming techniques. Simulation \& Games, v. 12, n. 2, p. 61-9, 1982.

MARzoLo, P.L. Juego educativo: quién sabe más de SIDA? Fduc. Antocuidado Salud, v. 6, n. 2, p. 38-42, 1989.

McClfraN, K. A new game show in the OR. Today's O.r. Nurse, v. 5, n. 7, p. 60, 1983.

NOWAK, B.I.; ADAMS, D.S. Staffing pursuits: an instructional game for new nurse mankgers. Nurs. Manag., v. 19, n. 11, p. 46-7, 1988.

PIERFY, D.A. Comparative simulation game research: stumbling blocks and steppingstones. Simulation \& Games, v. 8, n. 2, p. 255-67, 1977.

PLASTERER, H.H.; MILLS, N. Teach management theory - through fun and games. J. Nurs. Educ., v. 22, n. 2, p. 80-3, 1983.

ROSENDAHL, P. Self-direction for learners: an andragogical approach to nursing education. Nurs. Forum, v. 13, n. 2, p. 136-46, 1974.

ROTHROCK, J.C. Simulation games - playing to win and to learn. AORN J., v. 44, n. 5, p. 803-7, 1986.

ROTTET, s.M. Gaming as a learning strategy. J. Contin. Educ. Nurs., v. 6, n. 6, p. 22-5, 1974.

RUBEN, B.D. Toward a theory of experience-based instructions. Simulation \& Games, v. 8, n. 2, p. 211-31, 1977 .

SANCHEZ, A.L. et al. El juego como técnica de educación en salud. Educ. Antoouldado Salud, v. 5, n. 3, p. 8-12, 1988.

SHIDL, A.H.; DRESSRN, S. Gaming: a strategy to teach conflict regolution. J. Nurk. Iduc., v. 17, n. 5, p. 21-8, 1978. 
SILVA, J.R.; DECK, M.L. The gameg we play. J. Pediatr. Nurs., v. 4, n. 1, p. 59-61, 1989.

SLEFT, D.A.; CORBIN, D.F. Simulation gaming in health education. In: LAZES, P. Handbook of health education. Rockville, Aspen, 1979. cap. 10, p. 175-85.

; STADSKLEV, R. Annotated bibliography of simulations and games. Fealth Educ. Monogr., v. 5, p. 74-89. 1977. Supplement 1 .

SMITH, A. Management: all in the game. Nurs. Mirror, v. 157, n. 25, p. 18-22, 1983.

SMOYAK, S.A. Use of gaming simulation by health care professionals. Health Fduc. Monogr., v. 5, p. 11-7, Supplement 1 .

STEFANELLI, M.C. Engino de técnicas de comunicacão terapêutica enfermeira-paciente. Săo Paulo, 1985. 163 p. Tese (Doutorado) - Escola de Enfermagem da Universidade de São Paulo.

STEFANELLI, M.C. Comunicação enfermeira-paciente: teoria, ensino e pesquisa. Såo Paulo, 1990. 132 p. Tese (Livre-Docencia) - Escola de Enfermagem da Universidade de Sao Paulo.

SYLVESTER, M.J. Management games: a useful link between theory and practice. J. Nurs. Adm., Wakefield, v. 4, n. 4, p. 28-32, 1974.

THIAGARAJAN, S. Evaluation of simulations and games: a comprehensive procedure and a case history. Health Educ. Monogx., v. 5, p. 64-75, 1977. Supplement 1.

ULIONE, M.S. Simulation gaming in nursing education. J. Nurs. Educ., v. 22, n. 8, p. 349-51, 1983.

WALLJASPER, D. Games with goals. Nurse Educ., v. 7, n. 1, p. 15-8, 1982.

WASHBURN, A.; MCGINTY, R.T. The use of metro-apex in health administrations and planning education and training. Health Educ. Monogr., v. 5, p. 36-41, 1977. Supplement 1.

WHITE, G.B.; DAVIS, A.J. Teaching ethics using games. J. Adv. Nurs., v. 12, n. 5, p. 621-4, 1987.

WINNEY, R.; FORREST, F. The reality game. Nurs. Times, v. 79, n. 11, p. 64-5, 1983.

WOLF, M.S.; COGGINS, C.C. A workshop for development games in nursing. J. Contin. Educ. Nurs., v. 12, n. 3, p. 31-4, 1981.

WOLF, M.S.; DUFFY, M.E. Sinulations/games: a teaching strategies for nursing education. New York, National League for Nursing. 1979. 39 p. (Pub. no $23-1756$ ).

WODBERY, P.M.; HAMRIC, A.B. Prepare your unit to manage a with a mock: emergency excercise. Nursing, v. 11, n. 12, p. 32-4, 1981.

YANTZIE, N. Help-simulated disaster game. Can. Nurse, v. 76, n. 6, p. 33-6, 1980.

Recebido em 06/06/91 